\title{
ANALYSIS OF PUBLIC TRANSPORT SERVICES WITH VARIOUS CRITERIA
}

\author{
Marek BRANIŠ ${ }^{1 *}$, Matej ŠULÍK¹, Jakub TAKACS ${ }^{1}$, Tibor SCHLOSSER ${ }^{1}$
}

\section{Abstract}

With the current worldwide trend of increasing individual car traffic in urban road networks, public transport has become one of the key issues for the sustainable future of transport in cities, especially when the level of automobilization is growing rapidly. Many cities are already at the capacity limit of an existing road network. Therefore, many cities are trying to solve the question of how to improve the existing systems of public transport to become more attractive for their citizens. The quality of the public transport service from a passenger's point of view is not only about the number of links and their occupancy, but also about the time and distance availability of stops and stations. When we were creating the general master plan for one small Slovak town, we tried to take various criteria into account. Of course, it was also necessary to carry out traffic surveys to determine the occupancy of public transport systems, but equally important was to determine the isochrones and isodistances of the passengers. The lessons learned and complications that arose from the preparation and realization of the actual analysis of the results in the creation of the general master plan are set out in the contribution.

\section{Address}

1 Dept. of Transportation Engineering, Slovak University of Technology in Bratislava, Slovakia

* Corresponding author: marek.branis@stuba.sk

\section{Key words}

- Mobility, public transport

- Occupancy,

- Traffic survey,

- Accessibility of bus stops.

\section{INTRODUCTION}

With the current worldwide trend of increasing individual car traffic on urban road networks, public transport has become one of the key issues for the sustainable future of transport in cities. Some basic problems of urban street networks were published in [1]. The set of activities to define the purpose of public transport within a city is applied in land-use planning documentation, specifically in the transport master plan of a city $[2,3,4]$. Special details about public transport surveys are set out in [5]. The problems of creating traffic planning scenarios for small towns in Slovakia are in [6]. Sustainable mobility for urban areas was shown in [7]. This trend has not been avoided by the Slovak town of Šala and its districts. The unsustain- able growth of individual car traffic is visible on the roads, while the occupancy of the public transport does not reach the expected potential for passenger transport within the town of Sala [8]. To develop the principles of city transport policy, we could not omit the issue of public transport $[9,10,11]$. The aim was to analyze the data obtained from actual traffic in a qualified way and propose specific solutions in the area of transport infrastructure and transport services. Thanks to this data, we were able to optimize the accessibility of walking to bus stops in [13]. Based on the consideration of favorable development tendencies of the town, every general master plan defines the direction of the development of the transport infrastructure. For the purpose of the general master plan of the town of Šala, we divided the town into 7 zones and analysed their functions, Figure 1. 

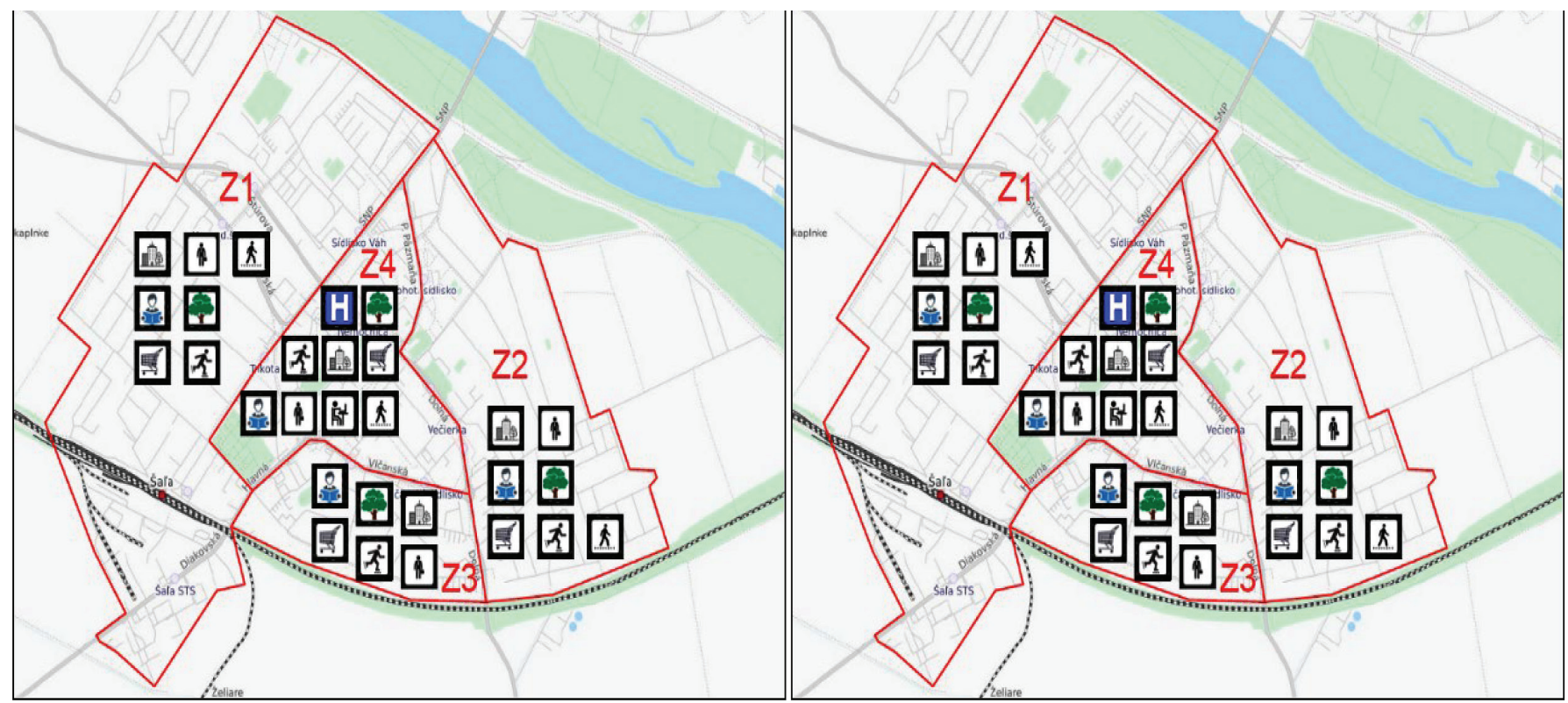

Fig. 1 Division of the town of Šal'a into zones with their functions

\section{PUBLIC TRANSPORT IN THE TOWN OF ŠALA AND ITS DISTRICTS}

To analyze the current state of Šala`s public transport, we wanted to use actual data from daily operations that had been collected during an average weekday. The public transport providers operating in the town of Šala gave us only a limited set of data from the actual operation of the transport. In the case of the rail transport, we received a set of train movements at the railway station of the town of Šal'a. In the case of the regional bus lines, the data given concerned entry and exit stops and the number of passengers on the lines beginning, ending or passing through the town of Šal'a. There is also a city bus line in the town of Šala, which operates between the districts of Šal'a and the railway station in both directions. During the working day, the line is operated by one bus all day and by a second bus during peak times. There are a total of 26 bus links in both directions. In the case of the bus lines in the town of Šala, just one single line is provided, with a uniform tariff which applies along the route. Therefore, it was not possible to determine the occupancy of the links according to the sales of bus tickets. This was the main reason why, as part of the Mobility Survey [12.] we also had to carry out a manual survey, which included counting the passengers on the town buses. The one

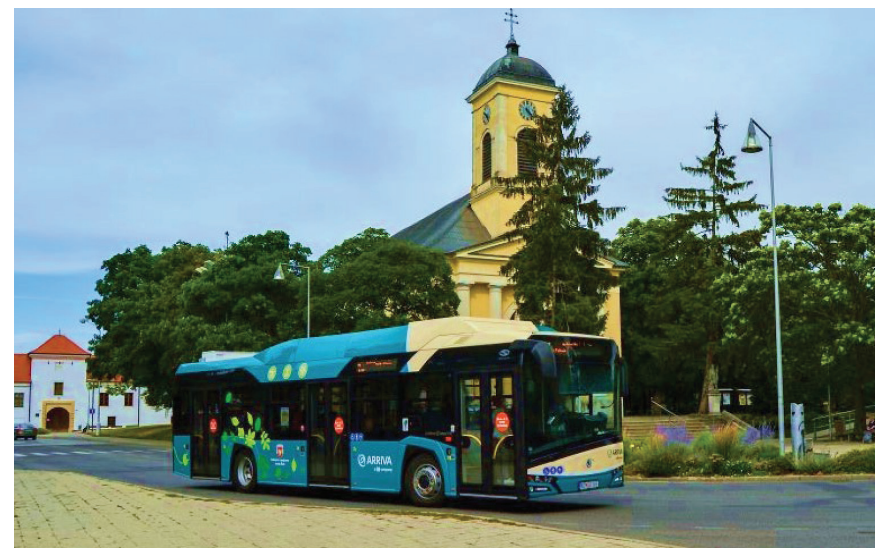

Fig. 2 Electric bus which operates the city bus line in the town of Šala and only city bus line connects the district of Veča with the railway station, and it has two main alternatives. It is primarily operated by a newly purchased electric bus, Fig. 2., which is a 12-meter-long vehicle with a normal capacity of 80 passengers. During the charging and during traffic peaks, the city bus line is operated by a classic diesel bus, with transfers from regional bus lines.

\section{ANALYSIS OF COLLECTED DATA FROM OPERATION OF THE PUBLIC TRANSPORT}

For the traffic survey, we needed an average working day during the week. It was carried out on Wednesday, 13.11.2019. During the survey, 3159 passengers were counted. In analyzing the occupancy rate, we considered the normal capacity as a reference value of the maximum capacity rate of the vehicle [5.]. That means an occupancy with a density of 5 passengers $/ \mathrm{m}^{2}$ for each type of vehicle, which the current link of the city bus line operated. According to the operating vehicles, we set the average value of the normal capacity, which represents 80 passengers per one city bus line link. Subsequently, we determined from this value the maximum utilization of each city bus line link in percentages. Based on the capacity analyses of each link, we can see during the morning rush hours, the highest occupancy rate of the public transport vehicle was approximately $40 \%$ of its capacity. This occupancy was reached in Link No. 10 with a departure at 6:05 from Šala, Veča to the railway station - Fig. 3.

On most of the bus links, the bus occupancy was lower than $30 \%$ of the vehicle's capacity, and there were also bus links that were completely empty. It is necessary to state that these cases were just bus links in the early morning and in the late evening. The diagram of the average occupancy of the vehicle is visible in Fig. 4. The reference value on the Y-axis represents the normal capacity of the vehicle, i.e., 80 passengers. According to this diagram, a 12-meter-long bus tends to be oversized.

The total daily occupancy of the city bus line is visible in Figure 5, where the occupancy for each direction of a line and for all 26 links together is visible for both directions. The reference value on the Y-axis represents the total capacity of the 26 bus links, which is 2080 passengers. The busiest section between two stops was between the Veča, Lúčna and Pohot. Stops the Sidlisko district stops, in the direction to the railway station, with a maximum occupancy 


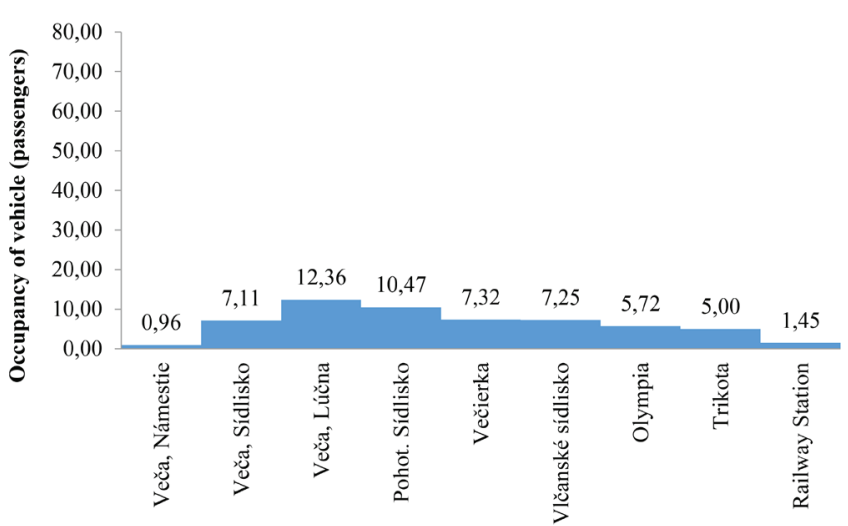

Fig. 4 Average occupancy of a city bus line along its route

of 483 passengers, represent less than $24 \%$ of the normal vehicle capacity.

Although the city bus line starts and respectively ends at the railway station, it is definitely not possible to discuss the ideal connection for passengers using trains. Due to the intervals of the city bus line, the ideal transfer is ensured primarily for express trains in the direction to and from the capital of Bratislava. In case of a train delay in the direction from Bratislava, the city bus waits for departure at the most 5 minutes.

Compared to the insufficient utilization of the city bus line, we noticed when we were analyzing the regional bus lines according to ticket sales a significant number of passengers traveling within the town of Šala using the regional bus lines, i.e., 198 passengers between the railway station and districts of the town during one average working day.

Due to the finding of the insufficient utilization of the town bus line, which is despite Šala's significant investment in the renewal of vehicles, we proceeded to an analysis of the route of the line and its stops through its accessibility by residents and potential passengers.

\section{ANALYSIS OF ACCESSIBILITY OF STOPS}

Based on observations in the town, field measurements, and functional analyses, we determined the average speed of a pedestrian. The

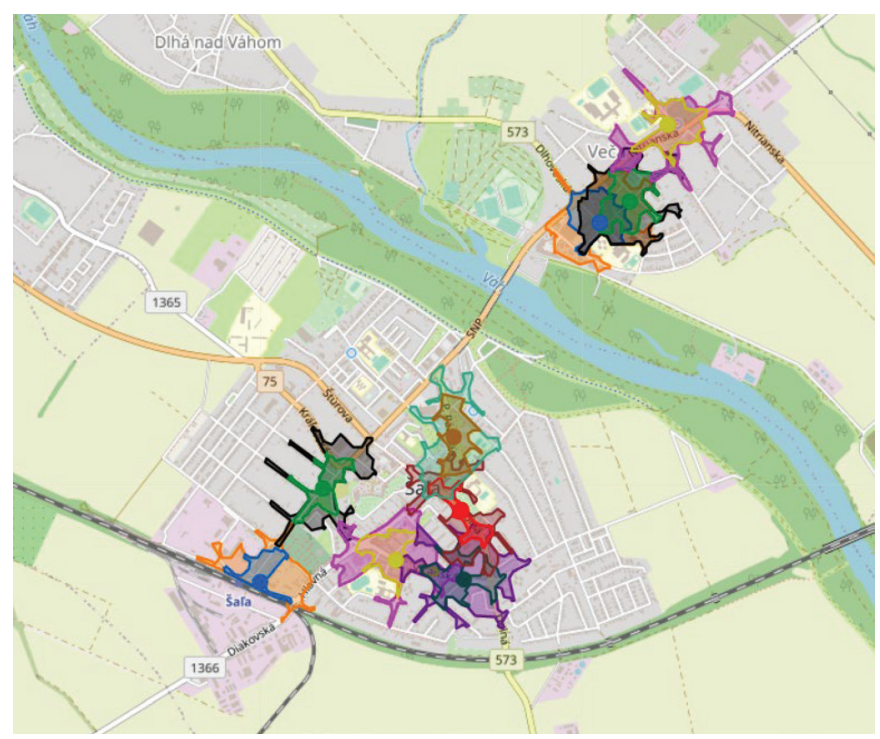

Fig. 6 Isochrones for 3 and 5 minutes

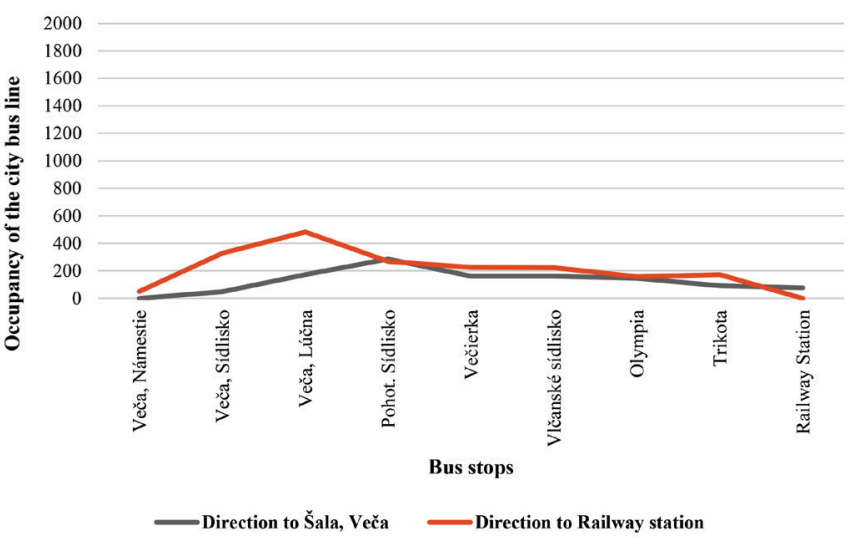

Fig. 5 Occupancy of the city bus line for each direction

average speed of pedestrians is an important indicator to determine accessibility by walking. We used the average speed of pedestrians to analyze the mutual distances between bus stops. As tools for our analysis, we chose isochrones and isodistances, see Fig. 6. Isodistances as well as isochrones connect various points on a terrain and have the equal value of a physical unit. The locations of sources were the bus stops of the city bus line as well as the stops of the regional bus lines. In a detailed analysis, we calculated isochrones for 2, 3, 5 and 10 minutes. We also calculated isodistances for 200 and $300 \mathrm{~m}$. In reverse calculations this means:

- $300 \mathrm{~m}$ represents 4 minutes and 23 seconds of walking; $200 \mathrm{~m}$ represents $2 \mathrm{~m}$ and 55 ;

- $3 \mathrm{~min}$. represents $205 \mathrm{~m}$; $5 \mathrm{~min}$. represents $342 \mathrm{~m}$; and $10 \mathrm{~min}$. represents $684 \mathrm{~m}$.

We consider the average speed of pedestrians to be $4.1 \mathrm{~km} / \mathrm{h}$. This speed was calculated for 4 categories - Tab. 1 .

The speed of the pedestrians for each category was set from various studies available. The speed of the pedestrians in the category under 30 years we achieved from terrain measurements directly in the town of Šal'a on sections between the existing bus stops. The speeds were measured by a mobile application called Endomondo [15], Fig. 7 .

We chose four categories because the area operated by the town bus line mainly consists of multifunctional zones, where functional sections of the town, i.e., living, work, services, and others, are combined. Due to those combined functions, we decided to proceed with the analysis with an average of four categories of walking speed.

The principle of drawing isolines in our investigated area, which consists of the built-up land of the town of Šal'a, is based on a background map. OpenStreetMap was used in our calculations. The background map reflects the transport network with crossroads, public spaces, pavements, etc. Pedestrians moving from their starting point to their destination have to overcome obstacles. The route of the pedestrians is affected by these obstacles, and the route is not straight but curved. Usually, the accessibility is described in a circular shape, but it is inexact on built-up land. A much better supposition for walk-

Tab. 1 Pedestrian walking speed category

\begin{tabular}{|l|l|}
\hline Type of pedestrian & Speed $(\mathbf{k m} / \mathbf{h})$ \\
\hline Children up to 7 years & 3.4 \\
\hline Young people under 30 years & 5.4 \\
\hline People in middle age between 30 and 50 years & 4.3 \\
\hline Older people up to 60 years & 3.2 \\
\hline
\end{tabular}




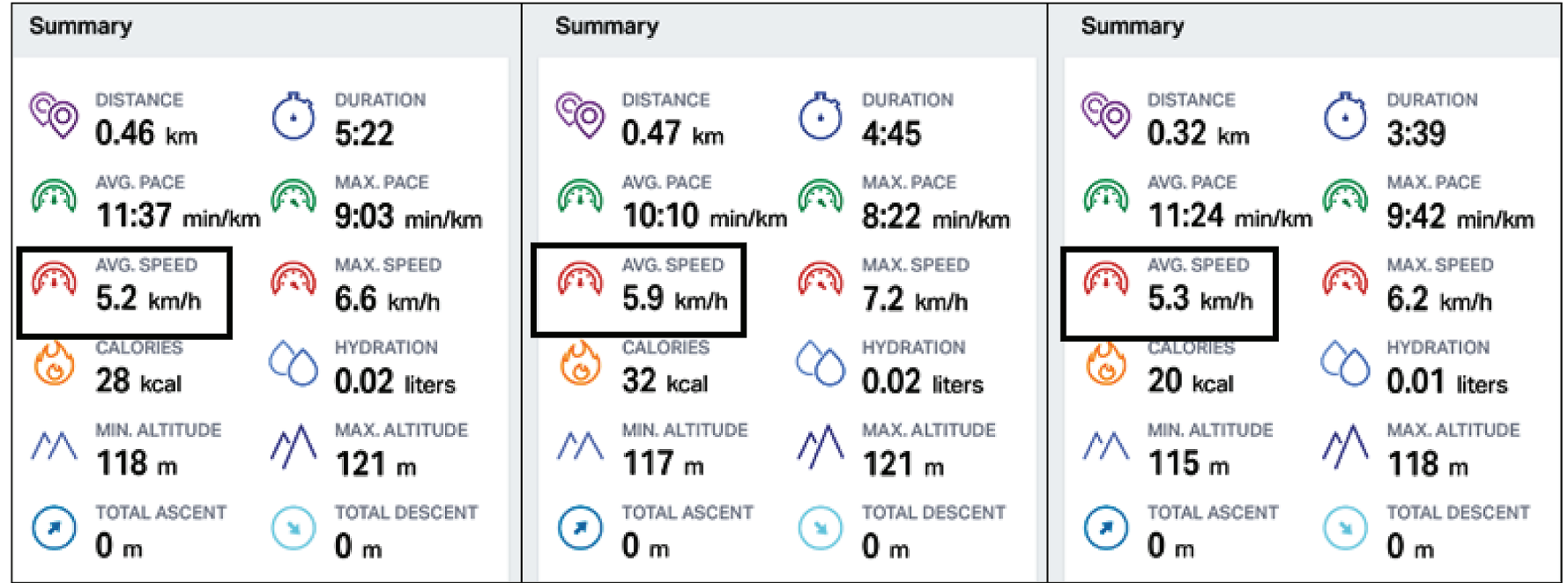

Fig 7. Output from the Endomondo mobile application

ing accessibility is represented by isolines. Isolines, i.e., isochrones or isodistances, help us to consider the geography of land, i.e., crossroads, construction sites, buildings, roads, and obstacles, which do not directly allow a walk-through route. Each possible route traveled for a specific time or distance from a certain point was calculated by Dijkstra's algorithm [14]. The connection of the points with an equal time value creates a isochrone. Similarly, the connection of points with equal distance values creates isodistances. Dijkstra's algorithm requires a background map, where the obstacles are defined, so isolines can be drawn. The precision of drawing isolines is based on the precision of the background map. For example, the area around Smetanova Street consists of family houses. However, family houses with a front yard/ back yard are private property, which is defined in the background map as an obstacle for pedestrians. Therefore isolines will not overrun family houses.

A similar case could occur if the construction site is in the area of interest, which is inaccessible to the public. The situation could

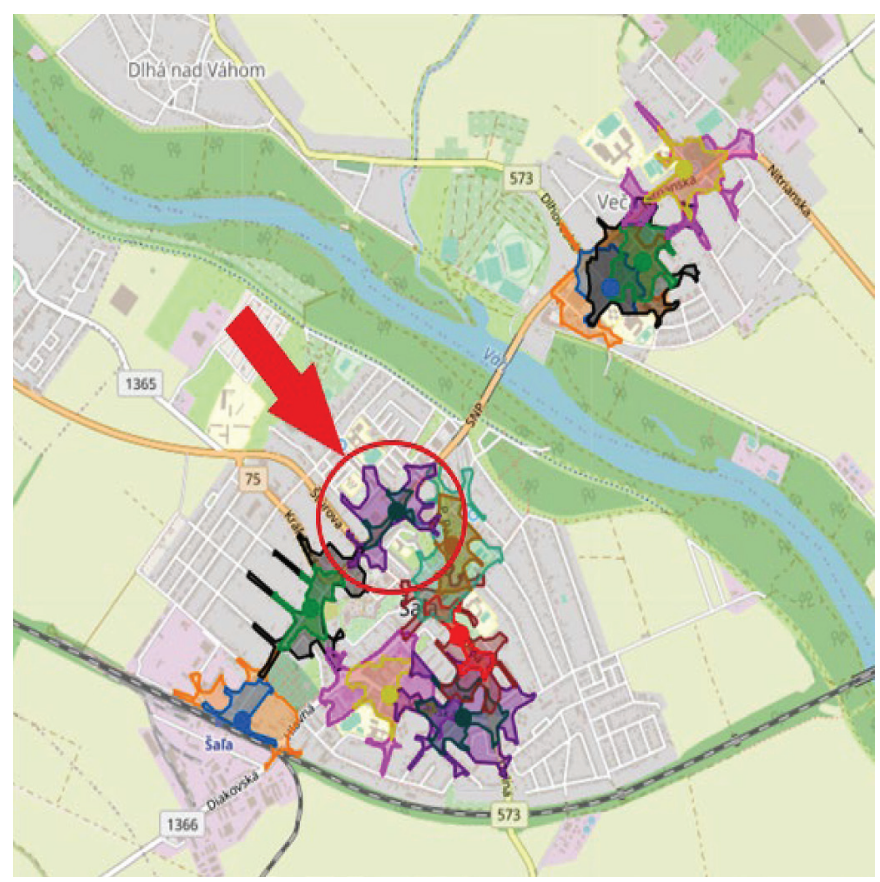

Fig. 8 Isochrones for 3 and 5 minutes - optimalized walking accessibility change in the future after completion of a building when it needs to be redefined in the background map. If the exterior, interior, or parterre will be opened to the public, the shape of the isoline will have to be changed.

From the isochrones drawn, the location of a bus stop with accessibility from the surrounding streets is obvious. On the one hand, in some parts of the town, the location of stops is undeniable, with no other changes possible. On the other hand, there is a spacious part of a town, which has accessibility for more than 5 minutes of walking, i.e., especially the area marked red, see Fig. 8, which is quite a big district with blocks of flats with the bus stop from 5 to 12 minutes away. From an analysis of the isochrones in this residential zone in Figs. 6 and 8, it is obvious that the addition of a bus stop in this location will improve the time availability of pedestrian transport and thus increase interest in public transport. Right now, only a bus stop for intercity buses is located there, which could also be used for city bus lines in the future.

We also analyzed the pedestrian accessibility from the railway station. The railway station is an important transport point in a town, and as was already mentioned in section 3 , the connection of the public transport to the trains is unsatisfactory. Therefore, due to the size

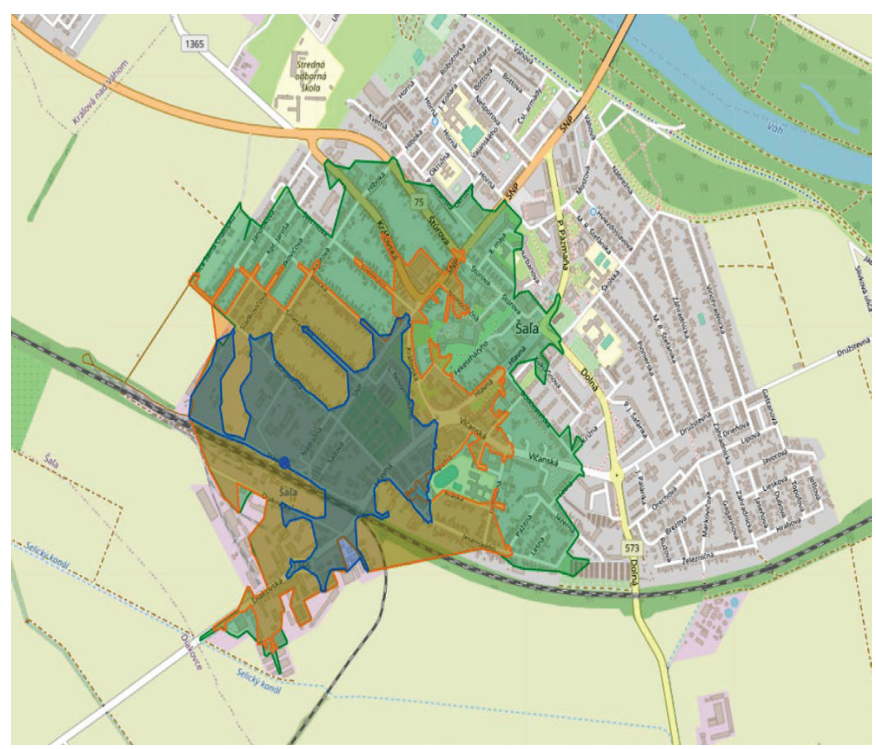

Fig. 8 Isochrones for 3 and 5 minutes - optimalized walking accessibility 


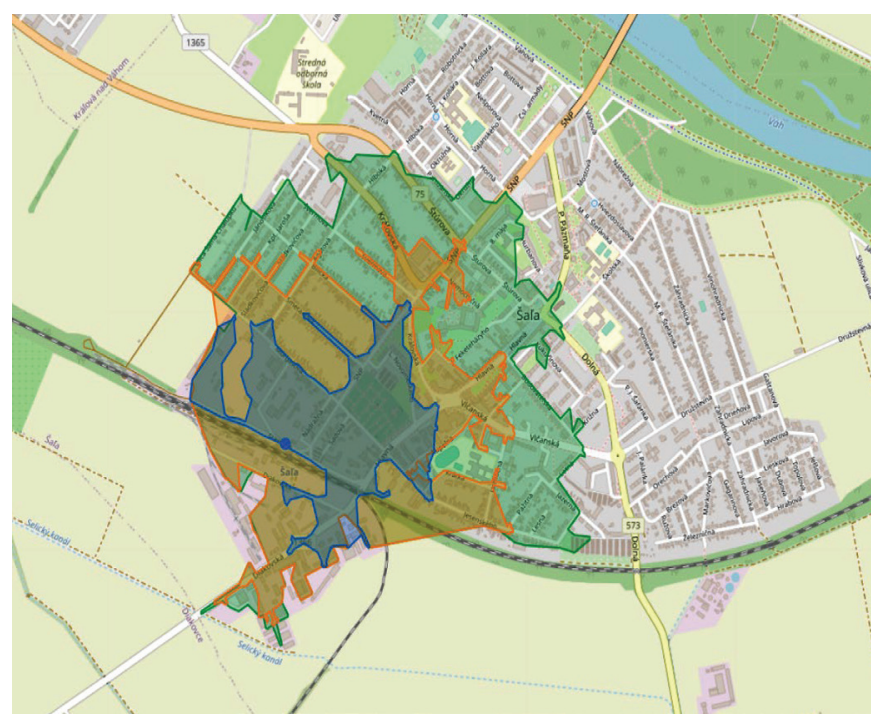

Fig. 9 Isochrones for 10, 15 and 20 minutes of walking acessibility from the railway station in the town

of the town, many people also prefer to walk if the weather conditions are suitable. Fig. 9 shows the isochrones for walking accessibility for times of 10,15 , and 20 minutes from the railway station.

Unfortunately, the districts of the town with a higher density of inhabitants with lots of blocks of flats have been uncovered by isochrones, which in practice means a lack of accessibility for more than 20 minutes. For many towns with a size similar to Šala, an important way to travel in a town is a bicycle. Therefore, we have also created isochrones for bicycle transport, where we considered the average speed of a cyclist to be $12 \mathrm{~km} / \mathrm{h}$. However, this value is theoretical, because the bicycle infrastructure in the town is available only on a few streets. On other streets, the cyclists have to use the road together with other traffic. We did not consider riding sidewalks in the isochrones, where cycling is restricted. Fig. 10 shows the isochrones for time availabilities of 10,15 , and 20 minutes using a bicycle from a railway station. From the picture, it is clear that the range of bicycle use covers not only practically the entire part of the town of Šala but also the villages in the neighborhood, i.e., Diakovce and Král'ová nad Váhom.

\section{CONCLUSION}

After analyzing the public transport in the town of Šal'a, we came to the conclusion that even though the town of Šal'a has one of the most modern public transport systems in Slovakia in terms of its vehicle fleet, its potential could be significantly greater than the existing range of public transport connections. The occupancy of public transport rarely exceeds $40 \%$ during the average working day. However, this low occupancy is not due to a lack of passenger interest, but rather to unattractive operating intervals. This low interest is confirmed by the number of passengers who use regional bus lines to travel across the urban area of Šal'a, or prefer a car, despite the good accessibility of public transport stops, which is evident from the isochrones created.

Similarly, the function of connecting the municipal bus line to the railway station often becomes irrelevant, because the bus line can provide a suitable transfer only for some train connections, and due to train delays, not very reliably. As a result, many residents prefer a car for their transport from their place of living in Šala to the railway station.

For improving the city public transport in the town of Sala, it would be more appropriate to use smaller capacity vehicles, but with

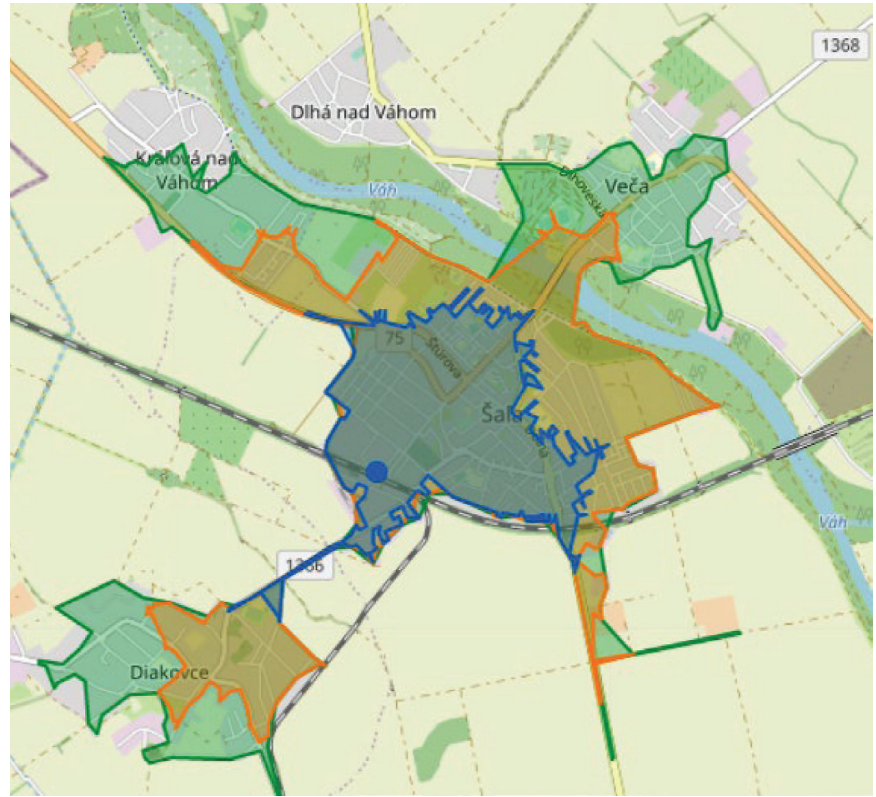

Fig. 10 Isochrones for cyclists - accessibility for 10, 15 and 20 minutes of cycling

a shorter frequency between connections. Thus it would be possible to establish transfers, respectively, from more passenger trains to and from Bratislava, which operate all day at regular intervals. For increasing use of the municipal bus line, there is a possibility of creating more bus route alternatives by also using the existing regional bus stops. By creating more route alternatives, the area of the public transport territory served will be increased, thus making the public transport more accessible, age-friendly as is described in [16], and more attractive for more residents.

The analysis of pedestrian availability by using isochrones in the municipal area of Šl'a showed us how significant the movement of pedestrians in towns the size of Šal'a is. The aim was to set out the individual distances and accessibilities for individual times. This proved to be a very useful tool in evaluating the location of public transport stops, where the entire area of the town should be optimally covered within a 5 minutes walking distance from the nearest stop. The analysis of isochrones for cyclists shows how significant the transport potential for bicycles could be in the town of this size if a suitable and safe bicycle infrastructure would be built.

An important disadvantage of this research was the fact that the results and conclusions achieved are based only on measurable physical data. The one and only criterion considered was the time availability, which we determined as an important indicator of the quality of life in the urban area. The results and conclusions do not reflect the personal preferences of the inhabitants of the city regarding their previous habits and their preferred comfort of the transport. 


\section{REFERENCES}

Braniš, M. - Schlosser, T. - Cápayová, S. - Zuzulová,A. - Hodáková, D.: Methodology of collecting data for evaluating public transport services. In: WMCAUS 2019 : abstract collection book of the World Multidisciplinary Civil Engineering - Architecture Urban Planning Symposium. Prague, 2019

Cápayová, S. - Štefunková, Z. - Unčík, S. - Zuzulová, A.: Requirements for pavement base layers with unbound granular material. In Slovak Journal of Civil Engineering. Vol. 27, No. 3 (2019), pp. 21-28. ISSN 1210-3896, WOS: 000489334200003 ; DOI: 10.2478/sjce-2019-0018.

Cihlářová, D. - Fencl, I. - Cápayová, S. - Pospíšil, P.: Use of adhesion promoters in asphalt mixtures. In Slovak Journal of Civil Engineering. Vol. 26, No. 1 (2018), pp. 19-24. ISSN 1210-3896, WOS: 000428512300003 ; DOI: 10.2478/sjce-2018-0003.

Dijkstra, E. W. - A note on two problems in connection with graphs. Numerische Mathematik, 1(1):269-271, 1959

Endomondo (mobile app.), https://www.endomondo.com/

Hegyi, S. - Schlosser, P. - Schlosser, T. - Schlosser, M.: Analysis of the traffic situation on the collectors to the town of Śal'a, profile traffic survey, transport technical study, DOTIS, s.r.o. - HELDIS, s.r.o., 2018

Kondrateva, E. - Siodorov, A. - Saprykin, O. - An Isochrone Based Public Transport Stops Optimization Technique, Department of Transportation Organization and Management, Samara National Research University

Schlosser, T. - Schlosser, P. Traffic engineering analysis in the preparation and reconstruction of urban roads. Slovak Journal of Civil Engineering. Vol. 26, No. 2018/2, pp. 35-39. ISSN 1210-3896

Schlosser, T. - Hodáková, D. - Schlosser, M. et al. : Traffic survey of the traffic routing in the town of Šal'a, Department of Transportation Engineering, SvF STU Bratislava - DOTIS Consult, s.r.o., 2018

Schlosser, T. - Schlosser, P. et al. : Traffic survey of the parking in the town of Šal'a - technical study, DOTIS Consult, s.r.o. Department of Transportation Engineering, SvF STU Bratislava, 2018

Schlosser, T.: Traffic-capacity assessments in the project planning documentation of road and urban engineering, In: Road Conference 2018, Slovak Road Administration, ISBN 978-80-9726113-9, pp. 53-61, 2018
Schlosser, T. - Hodáková, D. - Zuzulová, A. - Braniš, M. - Schlosser, P.: Impact of transport analysis on urbanization development in small towns of Slovakia. In: SGEM 2019. 19th International Multidisciplinary Scientific GeoConference. Volume 19. Nano, Bio and Green - Technologies for a Sustainable Future : conference proceedings. Albena, Bulgaria, pp. 479-486. ISSN 13142704. ISBN 978-619-7408-89-8, 2019

Schlosser, T.- Cápayová, S. - Hodáková, D. - Schlosser, P: Evaluation of Sustainable Mobility for Urban Development Projects with Traffic Engineering Tools - Example From Bratislava, In: SGEM 2018, 18th International Multidisciplinary Scientific GeoConference, Research Area: Green Design and Sustainable Architecture, Albena, Bulgaria, Vol. 18, Book 6.3, pp. 549-556, ISBN 978-619-7408-52-2, ISSN 1314-2704, 2018

Schlosser, T. - Schlosser, P. - Korfant, M.: Transport and urban principles of newly designed tram lines in the new downtown of Bratislava, In: Public transport conference - VOD 2019 : Collection of contributions from the international conference, Bratislava, Kongres STUDIO, CD-ROM, pp. 35-44. ISBN 97880-89565-40-5, 2019

Schlosser, T. - Schlosser, P. - Korfant, M. et al. : Newly designed tram lines in the new downtown of Bratislava - Traffic modelling and the determination of the modal split, Department of Transportation Engineering, SvF STU Bratislava and DOTIS Consult, s.r.o., 2019

Schlosser, T. - Schlosser, P. - Schlosser, M.: Traffic model as a tool for changing of modal split in Bratislava new city centre, In: Conference of Transport Science - Technology in Service of Sustainable Transport, Universitas-Győr Nonprofit Kft., Hungary, Szécsényi University Győr, 2018

Schlosser, T. - Takács, J. - Braniš M. - Schlosser, M. et al. : Household inquiry survey and public transport survey in the town of Šal'a, Department of Transportation Engineering, SvF STU Bratislava - DOTIS Consult, s.r.o., 2019

Strohmeier, F. - Barriers and their influence on the mobility behaviour of older pedestrians in urban areas: challenges and best practise for walkability in the city of Vienna, $6^{\text {th }}$ Transport Research Arena, April 18-21.4.2016 